\title{
Statistical Optimization Using Response Surface Methodology for Enhanced Tensile Strength of Polyethylene/Graphene Nanocomposites
}

\author{
Wan Nazri Wan Busu ${ }^{1,2^{*}}$, Ruey Shan Chen ${ }^{2^{*}}$, Dalila Shahdan ${ }^{2}$, Muhammad Jefri \\ Mohd Yusof $^{3}$, Mohamad Jani Saad ${ }^{1}$, Sahrim Ahmad ${ }^{2}$
}

${ }^{1}$ Food Science \& Technology Research Center, Malaysia Agricultural Research and Development Institut, PO Box 12101, 50774 Kuala Lumpur, MALAYSIA

${ }^{2}$ Materials Science Program, Faculty of Science and Technology,

Universiti Kebangsaan Malaysia, 43600 Bangi, Selangor, MALAYSIA

${ }^{3}$ Department of Chemical Sciences, Faculty of Science and Technology,

Universiti Kebangsaan Malaysia, 43600 Bangi, Selangor, MALAYSIA

*Corresponding Author

DOI: https://doi.org/10.30880/ijie.2021.13.06.010

Received 21 July 2021; Accepted 5 February 2021; Available online 31 August 2021

\begin{abstract}
Despite having remarkable features such as low density, ease of fabrication and recyclability, linear lowdensity polyethylene (LLDPE) has several drawbacks like poor stiffness and low creep resistance which fortunately can be improved by incorporating with other suitable nanofillers. In this study, graphene nanoplatelets (GNPs) that are well-known for its high surface area and superior stability were selected to reinforce the polymer network of LLDPE via melt blending. During mixing processing, the rotor speed, mixing temperature and mixing time parameters are manipulated with the aids of 5-level-3-factor central composite rotatable design (CCRD) in order to determine the optimization of processing parameters in preparing LLDPE/GNPs nanocomposites. The experimental data is fitted with the statistically significant quadratic model with $\mathrm{R}^{2}$ value of 0.8601 . The results showed that the tensile strength of LLDPE/GNPs nanocomposites could be extended to $24.80 \mathrm{MPa}$. The optimum processing parameters for preparation of LLDPE/GNPs nanocomposites were found to be at $101 \mathrm{rpm}$ rotor speed, $139.8^{\circ} \mathrm{C}$ of mixing temperature and 13.2 min of mixing time, resulting in LLDPE/GNPs nanocomposites with tensile strength of $24.11 \mathrm{MPa}$. Conclusively, our study has provided a novel statistical design of experiment to obtain the optimum processing parameters in preparing LLDPE/GNPs nanocomposites.
\end{abstract}

Keywords: Thermoplastics, nanofiller, polymer composites, central composite rotational design, tensile property

\section{Introduction}

Linear low-density polyethylene (LLDPE) is a product of ethylene copolymerization with longer-chain olefins that can be characterized by its short branches and linear structure, owing to its production at low temperature and pressure. LLDPE possesses interesting remarks to work with such as low density, easy to fabricate and recyclable [1]. However, the application of LLDPE is limited due to its low creep resistance, poor stiffness, poor electrical conductivity and barrier of oxygen [2].

Incorporating nanofillers into polymer matrix is one of the many ways to improve the undesirable properties of precursor components [3]. Seo et al. (2013) defines the term nanocomposites as the composition of polymer matrices 
and nanosize fillers that substantially maximize each other interfacial contact and interaction [4]. These nanocomposites have better electrical, mechanical and flame retardant properties than conventional composites [5, 6]. Graphene nanoplatelets (GNPs) are commonly used as nanofiller to enhance the interaction between GNPs sheets and polymer materials [7, 8]. GNPs are prepared from exfoliation of graphene that exhibit high surface area, thermal conductivity, mechanical strength and electron mobility [9, 10]. Piana \& Pionteck (2013) prepared their conductive polymer matrix based on graphite that can be used as electrodes for metal detection, temperature sensor, and antistatic coating [11]. Meanwhile, Popelka et al. (2018) suggested that polymer nanocomposites/GNPs in the form of sandwich structure fabricate are ideal for electromagnetic interference shielding application due to their strong flexible properties [12].

It has been reported that the addition of GNPs dramatically improves mechanical and thermal behavior of LLDPE [13]. High surface area and dispersion of GNPs in the matrix of LLDPE are responsible for better tensile strength, thermal stability, change in crystallinity and electrical properties of LLDPE/GNPs nanocomposites as reported by Khanam et al. (2016) [14]. The dispersion of GNPs as nanofillers in LLDPE matrix was expected to yield in the increase of mechanical properties of the resulting nanocomposites [15]. On the other hand, processing parameters are found to be influencing the quality of the end product [16]. Muthuraj et al. (2015) revealed that those independently controllable processing parameters such as temperature, mixing speed, pressure, size and amount of reinforcement might affect the performance of resulting composites [17]. Thus, optimizing processing parameters in preparing nanocomposites is crucial to obtain product with desired properties at optimum conditions.

Conventionally, one variation at time (OVAT) method is usually conducted to design sets of experimental optimization. However, OVAT has no definite solution to find the real best point of optimization prospect [18]. Response surface methodology (RSM) is a statistical tool, acting as alternative optimization method that offers reliable verified response model $[19,20]$. RSM is useful to minimize the number of experiment sets whilst predicting the interactions and possible nonlinear effects of each parameter [21, 22]. Chieng et al. (2012) used RSM to study the interaction between graphene loading and temperature in preparing polylactic acid/graphene composites. Their RSM model successfully predicted the response of tensile strength with $<2 \%$ error [23]. Meanwhile, by using RSM, Islam et al. (2102) managed to identify temperature as the predominant parameter that influenced the tensile strength of their polypropylene composites [24].

In this study, LLDPE/GNPs nanocomposites were prepared via melt-mixing post pre-mix method. Numerous researches have been conducted to investigate the optimization of various processing parameters and nanofiller loadings of LLDPE/GNP nanocomposites [3][15]. However, the optimization study of processing parameter using experimental modeling like RSM is still limited. In this work, the parameters effects (i.e rotor speed, temperature, mixing time) on the optimization of LLDPE/GNPs nanocomposites based on RSM via tensile strength were discussed.

\section{Experimental}

\subsection{Materials}

LLDPE (density: $0.918 \mathrm{gcm}^{-3}$, melt flow index: $1.0 \mathrm{~g} / \mathrm{min}$, melting temperature: $120-160^{\circ} \mathrm{C}$ ) was purchased from Exxon Mobile Chemical Corporation to be used as thermoplastic resin. GNPs (KNG-150) with thickness of 5 - $15 \mathrm{~nm}$, $5 \mu \mathrm{m}$ diameter, and density of $2.25 \mathrm{~g} / \mathrm{cm}^{3}$ were supplied by KNANO.

\subsection{Preparation of LLDPE/GNPs Nanocomposites}

LLDPE/GNPs (20:80 wt\%) nanocomposites were prepared using an internal mixer (Brabender Lab Station) at various rotor speed $(66-133 \mathrm{rpm})$, mixing temperature $\left(106.4-173.6^{\circ} \mathrm{C}\right)$ and mixing time $(9.6-16.4 \mathrm{~min})$. Next, hot and cold press process $\left(14 \mathrm{~mm} \times 14 \mathrm{~mm} \times 1 \mathrm{~mm}\right.$ spacer mold with temperature $180^{\circ} \mathrm{C}$ for upper and lower platens, compression pressure of $1 \mathrm{kpsi}$ ) (LP50 LABTECH Engineering Company) was used to compress the blends into sheets. For specimen testing, the sheets were cut according to ISO 37 specifications.

\subsection{Optimization using RSM}

The preparation of LLDPE/GNPs nanocomposites was conducted at different rotor speed, mixing temperature and mixing time that required 20 sets of experiment as suggested by RSM (Design Expert software 7.1.5). Central composite rotational design (CCRD) 5-level-3-factor was used to investigate the optimization of processing parameters in preparing LLDPE/GNPs nanocomposites. This CCRD design consisted of 20 sets of experiments with eight factorial points, six axial points, and six central points. Table 1 shows the actual code for experimental range and level for each variable. 
Table 1 - Experimental range and level for each variable

\begin{tabular}{|c|c|c|c|c|c|}
\hline \multirow{2}{*}{ Variable } & \multicolumn{5}{|c|}{ Level } \\
\hline & -2 & -1 & $\mathbf{0}$ & +1 & +2 \\
\hline Rotor speed, A (rpm) & 66 & 80 & 100 & 120 & 133 \\
\hline Mixing temperature, $\mathrm{B}\left({ }^{\circ} \mathrm{C}\right)$ & 106.4 & 120.0 & 140.0 & 160.0 & 173.6 \\
\hline Mixing time, $\mathrm{C}(\mathrm{min})$ & 9.6 & 11.0 & 13.0 & 15.0 & 16.4 \\
\hline
\end{tabular}

\subsection{Characterization}

Tensile test was carried out according to ASTM D638-03 using Testometric M350-10CT with $10 \mathrm{kN}$ load cell. At least 3 specimens were tested to get the mean value of tensile stress break (MPa). The morphology of the prepared nanocomposites was observed under scanning electron microscope (SEM Phillips XL 30). Samples were first coated with thin layer of gold before SEM observation.

Analysis of variance (ANOVA) with 99\% significance level was performed to determine the significant difference among independent variables. Those experimental and predicted values were compared to ensure the precision data of the statistical model. The model was validated though a series of validation experiments.

\section{Results and Discussion}

\subsection{Modelling and Analysis of Variance (ANOVA)}

The comparison between experimental and predicted values of tensile strength of LLDPE/GNPs nanocomposites is tabulated in Table 2. Those predicted values were obtained from model fitting feature in RSM/CCRD.

Table 2 - CCRD design for comparison between experimental and predicted tensile strength values

\begin{tabular}{|c|c|c|c|c|c|}
\hline \multirow[t]{2}{*}{ No. } & \multirow[t]{2}{*}{ Rotor speed, rpm } & \multirow{2}{*}{$\begin{array}{c}\text { Mixing } \\
\text { temperature, }{ }^{\circ} \mathrm{C}\end{array}$} & \multirow[t]{2}{*}{ Mixing time, min } & \multicolumn{2}{|c|}{ Tensile strength, MPa } \\
\hline & & & & Experimental & Predicted \\
\hline 1 & 80.00 & 160.00 & 15.00 & 20.24 & 19.81 \\
\hline 2 & 100.00 & 140.00 & 16.36 & 21.91 & 22.47 \\
\hline 3 & 120.00 & 160.00 & 15.00 & 19.45 & 19.14 \\
\hline 4 & 100.00 & 140.00 & 13.00 & 23.40 & 23.84 \\
\hline 5 & 100.00 & 140.00 & 13.00 & 24.78 & 23.84 \\
\hline 6 & 100.00 & 140.00 & 13.00 & 24.15 & 23.84 \\
\hline 7 & 100.00 & 140.00 & 9.64 & 21.79 & 21.97 \\
\hline 8 & 120.00 & 160.00 & 11.00 & 21.01 & 21.20 \\
\hline 9 & 100.00 & 173.64 & 13.00 & 19.50 & 19.95 \\
\hline 10 & 120.00 & 120.00 & 15.00 & 21.30 & 21.40 \\
\hline 11 & 80.00 & 120.00 & 15.00 & 21.61 & 20.90 \\
\hline 12 & 120.00 & 120.00 & 11.00 & 19.79 & 19.71 \\
\hline 13 & 133.64 & 140.00 & 13.00 & 19.65 & 19.46 \\
\hline 14 & 80.00 & 160.00 & 11.00 & 21.53 & 20.91 \\
\hline 15 & 66.36 & 140.00 & 13.00 & 17.86 & 18.78 \\
\hline 16 & 100.00 & 140.00 & 13.00 & 21.31 & 23.84 \\
\hline 17 & 100.00 & 106.36 & 13.00 & 19.33 & 19.61 \\
\hline 18 & 100.00 & 140.00 & 13.00 & 24.80 & 23.84 \\
\hline 19 & 80.00 & 120.00 & 11.00 & 18.44 & 18.24 \\
\hline 20 & 100.00 & 140.00 & 13.00 & 24.70 & 23.84 \\
\hline
\end{tabular}

Mathematically, the overall interaction among three processing parameters; rotor speed (A), mixing temperature (B) and mixing time (C) that affected tensile strength of LLDPE/GNPs nanocomposites can be presented as follows: 


$$
\begin{aligned}
& \text { Tensile strength }(\mathrm{MPa})=23.84+0.20 A+0.10 B+0.15 C-0.29 A B-0.24 A C \\
& -0.94 B C-1.67 A A-1.43 B B-0.57 C C
\end{aligned}
$$

In Equation (1), the positive value of the coefficient remarks synergistic effects while negative value denotes antagonistic effects for each variable. $\mathrm{R}^{2}$ coefficient value for this model is 0.8601 , signifying $86.01 \%$ of the total variations in the optimization are greatly influenced by the independent variables. Statistically, models with $\mathrm{R}^{2}>0.5$ indicate high correlation values among variables [25]. In this study, high $\mathrm{R}^{2}$ value obtained $(0.8601)$ clearly confides in the accuracy between experimental and predicted data.

Table 3 shows the ANOVA for the generated model. Our model revealed significant $p$ value $(p=0.003)$ and insignificant lack of fit $(p=0.892)$. Reportedly, a model is accepted when it has significant $p$ value $(p<0.01)$ and insignificant lack-of-fit $(p>0.01)$ [26].

Table 3 - Analysis of variance (ANOVA)

\begin{tabular}{lccccc}
\hline Source & $\begin{array}{c}\text { Sum of } \\
\text { squares }\end{array}$ & df & Mean square & $\boldsymbol{F}$-value & $\boldsymbol{P}$-value \\
\hline Model & 73.94 & 9 & 8.22 & 6.83 & 0.0030 \\
$A$ & 0.55 & 1 & 0.55 & 0.46 & 0.5142 \\
$B$ & 0.14 & 1 & 0.14 & 0.12 & 0.7412 \\
$C$ & 0.30 & 1 & 0.30 & 0.25 & 0.6270 \\
$A B$ & 0.69 & 1 & 0.69 & 0.57 & 0.4661 \\
$A C$ & 0.47 & 1 & 0.47 & 0.39 & 0.5477 \\
$B C$ & 7.09 & 1 & 7.09 & 5.89 & 0.0356 \\
$A^{2}$ & 40.04 & 1 & 40.04 & 33.30 & 0.0002 \\
$B^{2}$ & 29.62 & 1 & 29.62 & 24.63 & 0.0006 \\
$C^{2}$ & 4.73 & 1 & 4.73 & 3.93 & 0.0756 \\
Residual & 12.03 & 10 & 1.20 & & 0.8923 \\
Lack-of-fit & 2.79 & 5 & 0.56 & 0.30 & \\
Pure error & 9.23 & 5 & 1.85 & & \\
Corrected total & 85.97 & 19 & & & \\
\hline
\end{tabular}

Processing parameters involved in this optimization were found to be not dependent on one another based on the insignificant $p$ values for each rotor speed $(A)$, mixing temperature $(B)$, and mixing time $(C)$. However, rotor speed and mixing temperature had significant quadratic effects $\left(A^{2}\right.$ and $\left.B^{2}\right)$ on tensile strength of LLDPE/GNPs nanocomposites.

\subsection{Effects of Processing Parameters}

Three dimensional (3D) plotted graph that is generated from RSM CCRD model can be used to explain the interaction of parameters involved in the optimization process [25]. Besides, this 3D graph can determine the optimum condition for each variable. Z-axis in the $3 \mathrm{D}$ graph represents the responding variable (tensile strength) while another two from three variables (rotor speed, mixing temperature, mixing time) are plotted against it at $\mathrm{y}$-axis and $\mathrm{x}$-axis. Figure 1 (a-c) shows the 3D graphs illustrating the interactions among independent variables with responding variable. 


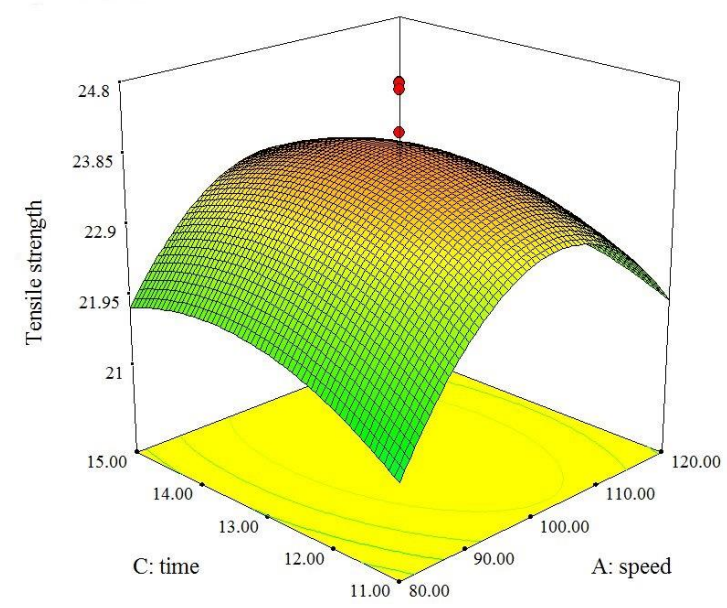

(a) 3D graph of tensile strength against speed and time

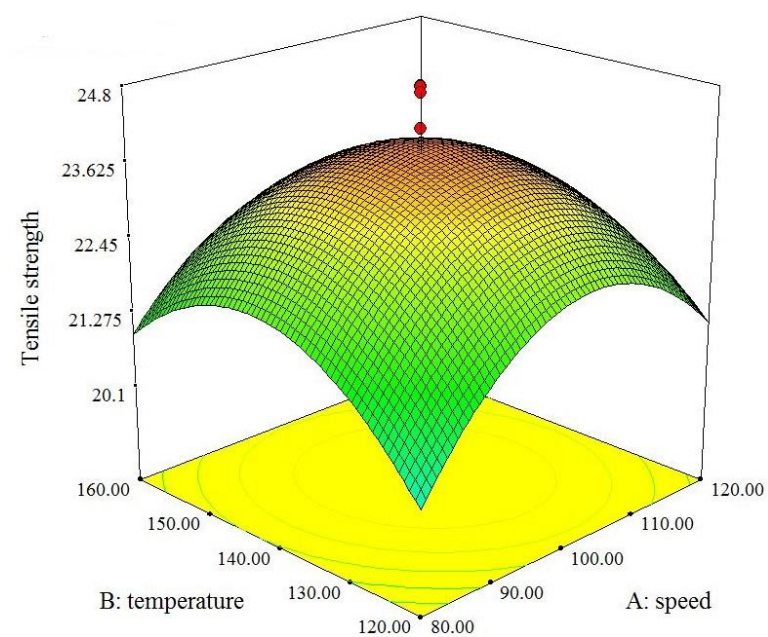

(b) 3D graph of tensile strength against speed and temperature

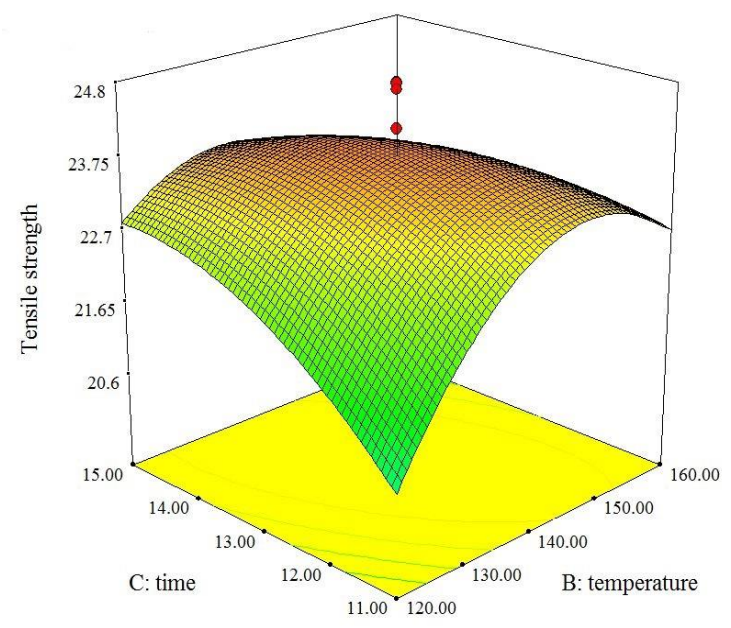

(c) 3D graph of tensile strength against temperature and time

Fig. 1 - 3D Graphs of tensile strength against independent variables

Increasing rotor speed during mixing of LLDPE and GNPs had directly increased the tensile strength of the nanocomposites. The addition of GNPs usually causes increment of viscosity in the polymer matrix, therefore, high rotor speed can aid in reducing the viscosity and better distribution of GNPS in the matrix [27]. However, exceeding 
certain speed (in this study $>100 \mathrm{rpm}$ ), detrimental impacts on the matrix properties might occur, leading to disruption of GNPs distribution [28].

Similarly, increasing mixing temperature would yield in better tensile strength of the nanocomposites until it reached $160{ }^{\circ} \mathrm{C}$ and higher. Poorly dispersed phase is commonly reported in a binary blend with low mixing temperature [29]. This low mixing temperature is known as the mixing enthalpy which will adversely affect the miscibility of the polymers thus hindering the successful blending [30]. Meanwhile, higher mixing temperature might thermally degrade the LLDPE that would result in a decrease in the tensile strength.

Likewise for mixing time, longer period of mixing resulted in better tensile strength of the nanocomposites up to $13 \mathrm{~min}$. Generally, longer mixing time can be associated with larger resistivity of volume as well as increasing dispersion progress of nanofillers in the matrix. At the beginning of mixing, slow decrease in resistivity is usually due to the formation of conductive network by the distribution of particulate filler in the polymer matrix. The same phenomenon might happen when much longer mixing time surpasses the ideal mixing time (13 min in this study) as the conductive network will reciprocate [31].

\subsection{Optimum Conditions}

The 'Optimization' feature in Design Expert was used to predict the optimum processing parameters in preparing LLDPE/GNPs nanocomposites by minimizing the values of processing parameters and maximizing the outputs of tensile strength. To confirm this prediction, one set of experiment was conducted according to the proposed optimum conditions. Apparently, both predicted and experimental data for preparing LLDPE/GNPs nanocomposites at optimum condition are recorded at almost similar value, as can be seen in Table 4.

Table 4 - The predicted and experimental tensile strength of LLDPE/GNPs nanocomposites prepared at optimum condition

\begin{tabular}{lccccc}
\hline Variables & & \multicolumn{3}{c}{ Tensile strength, MPa } & \multirow{2}{*}{ Deviation } \\
\cline { 1 - 4 } Speed, rpm & Temperature, $^{\mathbf{0}} \mathbf{C}$ & Time, min & Predicted & Experimental & \\
\hline 101 & 139.8 & 13.2 & 23.85 & 24.11 & 0.26 \\
\hline
\end{tabular}

To validate RSM models, a series of validation experiments (at least one) needs to be performed by manipulating any random values within the range of the independent variables (must be different from the initial set of CCRD design) [26]. Table 5 shows the comparison between predicted and experimental data for those validation experiments. The deviation values between predicted and experimental data were so narrow, indicating the acceptance of this empirical model to describe the effects of processing parameters on the tensile strength of LLDPE/GNPs nanocomposites.

Table 5 - Model validation

\begin{tabular}{ccccccc}
\hline No. & \multicolumn{3}{c}{ Variables } & \multicolumn{2}{c}{ Tensile strength, MPa } & Deviation \\
\cline { 2 - 5 } & Speed, rpm & $\begin{array}{c}\text { Temperature, } \\
\mathbf{0} \mathbf{C}\end{array}$ & Time, min & Predicted & Experimental & \\
\hline 1 & 90 & 140 & 13 & 23.32 & 22.91 & 0.41 \\
2 & 120 & 140 & 13 & 22.37 & 22.35 & 0.02 \\
3 & 100 & 140 & 12 & 23.62 & 23.41 & 0.21 \\
\hline
\end{tabular}

\subsection{Morphology of LLDPE/GNPs}

Theoretically, incorporating nanofillers in a polymer matrix will improve the mechanical properties and structural integrity of nanocomposites when the light weight and flexibility of both components are combined [32]. The surfacevolume ratio of the polymer matrix will also be increased that eventually increases the tensile strength of end product [33]. Based on the SEM micrographs in Figure 2, the LLDPE/GNPs nanocomposites prepared from the optimum conditions displayed more uniform dispersion of GNPs in the LLFPE matrix, hence explaining higher tensile strength than nanocomposites prepared from different processing parameters conditions. Young et al. (2017) reported similar findings when their nanocomposites exhibit significantly better mechanical properties as the GNPs were more dispersed in the polymer matrix [34]. GNPs have been reported to influence the crystal nucleation and microstructure of the nanocomposites that unsurprisingly, would improve their tensile strength [35]. 


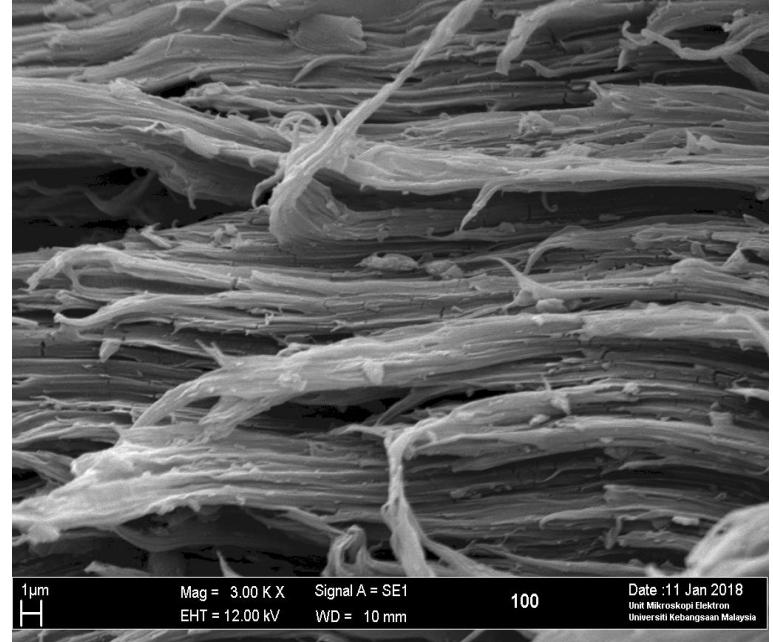

(a)

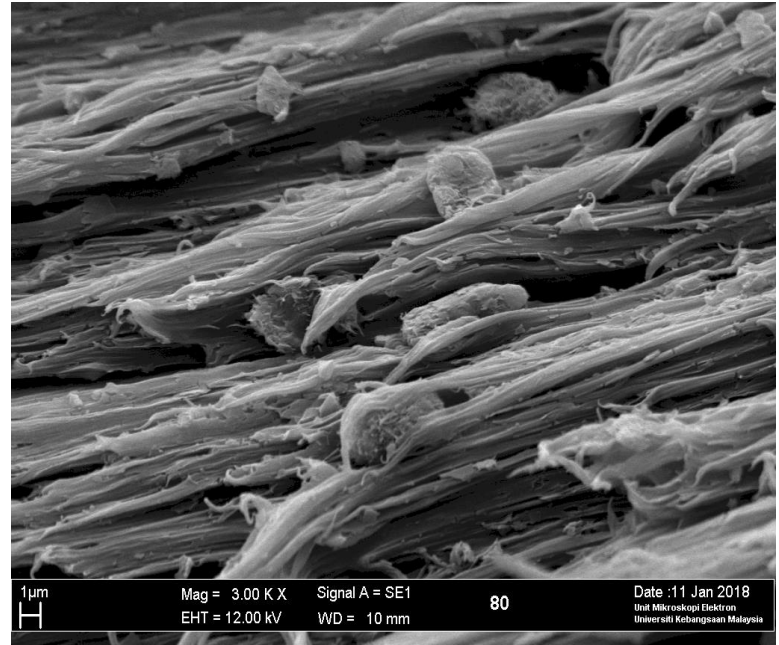

(b)

Fig. 2 - SEM micrographs of (a) LLDPE/GNPs with tensile strength of 24.11 MPa (optimum conditions) and (b) LLDPE/GNPs with tensile strength of $9.92 \mathrm{MPa}$

\section{Conclusion}

LLDPE/GNPs nanocomposites were successfully prepared and optimized using RSM based on the manipulation of rotor speed, mixing temperature and mixing time. High $\mathrm{R}^{2}$ value $(0.8601)$ verified that the experimental and model predicted data to be highly matched. The optimum processing parameter in preparing LLDPE/GNPs nanocomposites was reported at $101 \mathrm{rpm}$ rotor speed, $139.8{ }^{\circ} \mathrm{C}$ mixing temperature and 13.2 min mixing time that yielded LLDPE/GNPs nanocomposites with tensile strength of $24.11 \mathrm{MPa}$. Based on ANOVA, the generated model could be used to predict the tensile strength of LLDPE/GNPs nanocomposites at any given values within the range of processing parameters. For future study, more variables could be explored to optimize the processing parameters in preparing LLDPE/GNPs nanocomposites such as reaction pressure, screw system as well as LLDPE and GNPs loadings.

\section{Acknowledgement}

We would like to thank Universiti Kebangsaan Malaysia (UKM) for funding this experiment under FRGS grant (FRGS/1/2018/STG07/UKM/01/2) and Centre for Research and Instrumentation (CRIM) UKM for providing instrumentations and facilities.

\section{Conflict of Interest}

The authors declare no conflict of interest.

\section{References}

[1] Nabizadeh, N., Zohuri, G. H., Khoshsefat, M., Ramezanian, N., \& Ahmadjo, S. (2018). Ethylene/1-hexene copolymerization and synthesis of lldpe/nanocarbon composite through in situ polymerization. Polymer Science, Series B, 60(1), 122-129

[2] Anderson, K. S., Lim, S. H., \& Hillmyer, M. A. (2003). Toughening of polylactide by melt blending with linear low - density polyethylene. Journal of Applied Polymer Science, 89(14), 3757-3768

[3] Khobragade, P. S., Hansora, D. P., Naik, J. B., \& Chatterjee, A. (2016). Flame retarding performance of elastomeric nanocomposites: A review. Polymer Degradation and Stability, 130, 194-244

[4] Seo, H. M., Park, J. H., Dao, T. D., \& Jeong, H. M. (2013). Compatibility of functionalized graphene with polyethylene and its copolymers. Journal of Nanomaterials, 2013, 113

[5] Rafeie, O., Razavi-Aghjeh, M. K., Tavakoli, A., Salami-Kalajahi, M., Jameie-Oskooie, A., \& Ghayoumi, M. (2019). Study on crystalline structure of poly (vinylidene fluoride)/polyethylene/graphene blend nanocomposites. Polymer Composites, 40(11), 4402-4415

[6] Mahmoudian, S., Wahit, M. U., Imran, M., Ismail, A. F., \& Balakrishnan, H. (2012). A facile approach to prepare regenerated cellulose/graphene nanoplatelets nanocomposite using room-temperature ionic liquid. Journal of Nanoscience and Nanotechnology, 12(7), 5233-5239

[7] Kashi, S., Gupta, R. K., Baum, T., Kao, N., \& Bhattacharya, S. N. (2016). Dielectric properties and electromagnetic interference shielding effectiveness of graphene-based biodegradable nanocomposites. Materials \& Design, 109, 68-78 
[8] Ahmad, S. R., Xue, C., \& Young, R. J. (2017). The mechanisms of reinforcement of polypropylene by graphene nanoplatelets. Materials Science and Engineering: B, 216, 2-9

[9] Mohan, V. B., Lau, K., Hui, D., \& Bhattacharyya, D. (2018). Graphene-based materials and their composites: a review on production, applications and product limitations. Composites Part B: Engineering, 142, 200-220

[10] Stürzel, M., Kempe, F., Thomann, Y., Mark, S., Enders, M., \& Mülhaupt, R. (2012). Novel graphene UHMWPE nanocomposites prepared by polymerization filling using single-site catalysts supported on functionalized graphene nanosheet dispersions. Macromolecules, 45(17), 6878-6887

[11] Piana, F., \& Pionteck, J. (2013). Effect of the melt processing conditions on the conductive paths formation in thermoplastic polyurethane/expanded graphite (TPU/EG) composites. Composites Science and Technology, 80, 39-46

[12] Popelka, A., Khanam, P. N., \& AlMaadeed, M. A. (2018). Surface modification of polyethylene/graphene composite using corona discharge. Journal of Physics D: Applied Physics, 51(10), 105302

[13] Tian, G., Liu, J., Sun, T., Wang, X., Wang, X., Hu, H., Wang, D. (2018). The effects of carbon materials with different dimensionalities on the flow instabilities of LLDPE (linear low density polyethylene). Polymer, 142, $144-154$

[14] Khanam, P. N., AlMaadeed, M. A., AlMaadeed, S., Kunhoth, S., Ouederni, M., Sun, D., Mayoral, B. (2016). Optimization and prediction of mechanical and thermal properties of graphene/LLDPE nanocomposites by using artificial neural networks. International Journal of Polymer Science, 2016

[15] Biswas, S., Fukushima, H., \& Drzal, L. T. (2011). Mechanical and electrical property enhancement in exfoliated graphene nanoplatelet/liquid crystalline polymer nanocomposites. Composites Part A: Applied Science and Manufacturing, 42(4), 371-375

[16] Salmoria, G. V, Leite, J. L., Ahrens, C. H., Lago, A., \& Pires, A. T. N. (2007). Rapid manufacturing of PA/HDPE blend specimens by selective laser sintering: microstructural characterization. Polymer Testing, 26(3), 361-368

[17] [Muthuraj, R., Misra, M., Defersha, F., \& Mohanty, A. K. (2016). Influence of processing parameters on the impact strength of biocomposites: A statistical approach. Composites Part A: Applied Science and Manufacturing, $83,120-129$

[18] Rostamiyan, Y., Fereidoon, A., Mashhadzadeh, A. H., Ashtiyani, M. R., \& Salmankhani, A. (2015). Using response surface methodology for modeling and optimizing tensile and impact strength properties of fiber orientated quaternary hybrid nano composite. Composites Part B: Engineering, 69, 304-316

[19] Aldahdooh, M. A. A., Bunnori, N. M., \& Johari, M. A. M. (2014). Influence of palm oil fuel ash on ultimate flexural and uniaxial tensile strength of green ultra-high performance fiber reinforced cementitious composites. Materials \& Design, 54, 694-701

[20] Oladele, I. O., \& Agbabiaka, O. G. (2015). Investigating the influence of mercerization treatment of sisal fiber on the mechanical properties of reinforced polypropylene composites and modeling of the properties. Fibers and Polymers, 16(3), 650-656

[21] Shokuhfar, A., Khalili, S. M. R., Ghasemi, F. A., Malekzadeh, K., \& Raissi, S. (2008). Analysis and optimization of smart hybrid composite plates subjected to low-velocity impact using the response surface methodology (RSM). Thin-Walled Structures, 46(11), 1204-1212

[22] Hussain, S. A., Pandurangadu, V., \& Palanikuamr, K. (2011). Mechanical properties of green coconut fiber reinforced HDPE polymer composite. International Journal of Engineering Science and Technology, 3(11), 79427952

[23] Chieng, B. W., Ibrahim, N. A., \& Yunus, W. M. Z. W. (2012). Optimization of tensile strength of poly (lactic acid)/graphene nanocomposites using response surface methodology. Polymer-Plastics Technology and Engineering, 51(8), 791-799

[24] Islam, M. R., Beg, M. D. H., Gupta, A., \& Mina, M. F. (2013). Optimal performances of ultrasound treated kenaf fiber reinforced recycled polypropylene composites as demonstrated by response surface method. Journal of Applied Polymer Science, 128(5), 2847-2856

[25] Yusof, M. J. M., Tahir, N. A. M., Firdaus, F., \& Yusoff, S. F. M. (2018). Pengoptimuman parameter untuk penurunan diimida getah asli cecair dalam sistem hidrazin hidrat/hidrogen peroksida menggunakan kaedah rangsangan permukaan (RSM). Sains Malaysiana, 47(9), 2055-2061

[26] Tahir, N. A. M., Idris, M. S. F., Yusof, M. J. M., \& Yusoff, S. F. M. (2018). Penghidrogenan getah asli cecair menggunakan sistem mangkin selenium. Sains Malaysiana, 47(9), 2073-2082

[27] Heidarzadeh, A., Khodaverdizadeh, H., Mahmoudi, A., \& Nazari, A E. (2012). Tensile behavior of friction stir welded AA 6061-T4 aluminum alloy joints. Materials \& Design, 37, 166-173

[28] Noorunnisa Khanam, P., AlMaadeed, M. A., Ouederni, M., Mayoral, B., Hamilton, A., \& Sun, D. (2016). Effect of two types of graphene nanoplatelets on the physico-mechanical properties of linear low-density polyethylene composites. Advanced Manufacturing: Polymer \& Composites Science, 2(2), 67-73

[29] Saberian, M., Ghasemi, F. A., Ghasemi, I., \& Daneshpayeh, S. (2019). Investigation on tensile properties of epoxy/graphene nano-platelets/carboxylated nitrile butadiene rubber ternary nanocomposites using response surface methodology. Nanomaterials and Nanotechnology, 9, 1847980419855842 
[30] Van Bruggen, E. P. A., Koster, R. P., Picken, S. J., \& Ragaert, K. (2016). Influence of processing parameters and composition on the effective compatibilization of polypropylene-poly (ethylene terephthalate) blends. International Polymer Processing, 31(2), 179-187

[31] Das, N. C., Chaki, T. K., \& Khastgir, D. (2002). Effect of processing parameters, applied pressure and temperature on the electrical resistivity of rubber-based conductive composites. Carbon, 40(6), 807-816

[32] Li, B., \& Zhong, W.-H. (2011). Review on polymer/graphite nanoplatelet nanocomposites. Journal of Materials Science, 46(17), 5595-5614

[33] Roshan, M. J., Jeevika, A., Bhattacharyya, A., \& Shankaran, D. R. (2018). One-pot fabrication and characterization of graphene/PMMA composite flexible films. Materials Research Bulletin, 105, 133-141

[34] Young, R. J., Liu, M., Kinloch, I. A., Li, S., Zhao, X., Vallés, C., \& Papageorgiou, D. G. (2018). The mechanics of reinforcement of polymers by graphene nanoplatelets. Composites Science and Technology, 154, 110-116

[35] Inuwa, I. M., Hassan, A., Samsudin, S. A., Haafiz, M. K. M., Jawaid, M., Majeed, K., \& Razak, N. C. A. (2014). Characterization and mechanical properties of exfoliated graphite nanoplatelets reinforced polyethylene terephthalate/polypropylene composites. Journal of Applied Polymer Science, 131(15) 